\title{
A STUDY OF ERRORS IN ${ }^{14} \mathrm{C}$ DATES OF PEAT AND SEDIMENT
}

\author{
INGRID U OLSSON
}

Department of Physics, Uppsala University, S-751 21 Uppsala, Sweden

ABSTRACT. It is a well-established fact that ${ }^{14} \mathrm{C}$ dates from lake sediments are usually too old because of contamination with allochthonous material and/or due to discrete reservoir effects. The latter can occur in soft water lakes and may be examined by the ${ }^{14} \mathrm{C}$ measurement of aqueous plants or the carbon dissolved and suspended in the water column.

Some plants assimilate $\mathrm{CO}_{2}$ from the sediment. Their ${ }^{14} \mathrm{C}$ activity is then dependent on the sediment accumulation rate and nutrients stored in the root system may also contribute misleading results. If water is filtered through ultra-fine membranes and then treated chemically, several fractions can be isolated for dating. The present study shows that the ${ }^{14} \mathrm{C}$ activity of such fractions varies widely but with the weighted mean indicating an overall deficiency. Even the water from a raised bog evidences a ${ }^{14} \mathrm{C}$ deficiency relative to contemporary atmospheric $\mathrm{CO}_{2}$.

Charcoal from an archaeologic site and peat from corresponding layers in a nearby bog have yielded significantly different ages. The fact that the Cladium peat was from a very calcareous area is significant. The risk of contamination by younger root material is also documented.

\section{INTRODUCTION}

In order to investigate the apparent age of 300 to 400 years detected in the sediment of Lake Långa Getsjön (Olsson \& Florin, 1980) efforts were made to collect submerged modern plants. However, it proved difficult to obtain enough material because of the dystrophic character of the lake. As an alternative, lake water was collected and filtered. This approach was later extended to a fen (part of Vitmossen), the lagg of a peat bog (another part of Vitmossen), the vicinity of the lake, and a raised bog (Ryggmossen) near Uppsala.

\section{SAMPLINC}

A boat pump was used to suck up water into $25 \mathrm{~L}$ plastic bottles. Between 150 and $300 \mathrm{~L}$ were collected for each sample and transported directly to Uppsala. The water was stored in a room somewhat cooler than the laboratory until treated.

A canoe was used in the collection of lake water and the fen sampled from a hollow when the ice was just thick enough to support the author. Other fen and lagg water samples were taken in late autumn by using a ladder supporting planks as a collection platform. Water from the raised bog was taken in winter through a hole bored in the snow-covered ice of a hollow. In this instance the snow had started to thaw and the sample recovered seemed to derive to a great extent from the melt water.

\section{SAMPLE TREATMENT}

Except for the lake sample, the water was initially filtered through a quartz wool layer in a Büchner funnel. The retained material $(\mathrm{QW})$ was pretreated by the addition of $\mathrm{HCl}$, if necessary, to ensure that the sample was acid before being dried. The water with fine particles was then subjected to ultrafiltration. After some trial and error we chose a Diaflo YM10 membrane with a nominal molecular weight cut-off of 10,000. The filtrate (SOLFA), did not show any visible precipitate when $\mathrm{HCl}$ was added 
TABLE 1

Organic carbon content in $\mathrm{gmol} / \mathrm{m}^{3}$ of the investigated water samples

\begin{tabular}{lllccc}
\hline & & \multicolumn{3}{c}{ Fraction } \\
\cline { 3 - 6 } Sample type & \multicolumn{1}{c}{ Locality } & INSP & SOLHA & SOLFA & QW \\
\hline Lake water & Långa Getsjön & 0.15 & 0.05 & 0.47 & \multirow{2}{*}{0.76} \\
Fen water & Vitmossen & 0.02 & 0.09 & 1.24 & 0.2 \\
Lagg water & Vitmossen & 0.02 & 0.007 & 0.71 & 0.2 \\
Bog water & Ryggmossen & 0.006 & 0.003 & 0.07 & 0.07 \\
\hline
\end{tabular}

although a slight color change was perceptible. Thus, its behavior resembled that of fulvic acid. The solution was evaporated down to a black sample which, except for the bog, had a carbon content equivalent to ca $10 \mathrm{~g} \mathrm{per} \mathrm{m}^{3}$ water (Table 1). On combustion, about half of the dry samples remained as ash and this component has not been microscopically investigated in all cases. The slurry, residue retained on the Diaflo filter was centrifuged to yield a precipitate (INSP), and a dark reddish or brownish liquid. The liquid was acidified with $\mathrm{HCl}$ to a $\mathrm{pH}$ of $\leqq 2$ to obtain a precipitate (SOLHA), similar to humic acid.

The yield for the fractions (INSP) and (SOLHA) differed between the samples as shown in Table 1. The (SOLFA) fractions of all four water samples contained much more carbon than the (INSP) and (SOLHA) together and the lake water had a smaller carbon concentration than the fen and the lagg water. No direct comparison with the raised bog should be made on the total carbon content since the bog seemed frozen to the bottom and, as already intimated, the water was not wholly representative. The $(\mathrm{QW})$ fraction is of interest only for the ${ }^{14} \mathrm{C}$ activity, since the amount collected varied due to it blocking the pump filter.

\section{${ }^{14} \mathrm{C}$ MEASUREMENTS}

The activity measurements, which were started in March 1982 and finished in May 1984, used gas counting in Proportional Counter 4, except for one sample, Ryggmossen (SOLHA). This was measured in November 1983 by Göran Possnert using the Uppsala Tandem Accelerator. Magnesium was used to reduce the carbon dioxide to carbon which was then dissolved in iron. Thus, the result derives from measurements made during the adjustment of the accelerator and before a more efficient source preparation was adopted. Most of the gas samples prepared for this investigation had to be diluted to allow measurement in the proportional counter. Counting times (between 2 and 12 24-hr periods per sample) were chosen to obtain acceptable statistical uncertainties (Fig 1). In three cases, the spread of individual counting periods was determined (Stuiver, 1982) and the ratio (Fig 2) received sigma to expected sigma $\left(\sigma_{\mathrm{R}} / \bar{\sigma}\right)$ is 1.5 in one case, 1.0 in another, and 0.7 in the third.

\section{RESULTS}

All three fractions from the Lake Långa Getsjön have ${ }^{14} \mathrm{C}$ activities that are well below the atmospheric activity for the corresponding year (Fig 3). 
It is assumed that dissolved carbon is released from the nearby Getsjö Bog (Olsson \& Florin, 1980). The (QW) fraction of the fen is well below, whereas those of the lagg and the raised bog are very close to the atmospheric ${ }^{14} \mathrm{C}$ activity. Moreover, the (INSP) fraction of the lagg has about the same activity as the atmosphere whereas that of the fen is well above and that of the raised bog below the atmospheric ${ }^{14} \mathrm{C}$ activity. The accelerator measurement of the fraction (SOLHA) from Ryggmossen yielded an activity value slightly above the AD 1950 standard and the fen a significantly lower activity than the contemporary atmospheric activity. The fraction (SOLHA) of the lagg seems to have some excess activity over the atmosphere but this is just a little more than $+2 \sigma$. The fraction (SOLFA) of the lagg may reflect the atmospheric activity, although it is most probably lower, whereas for the fen and the raised bog, the comparable activities are certainly less.

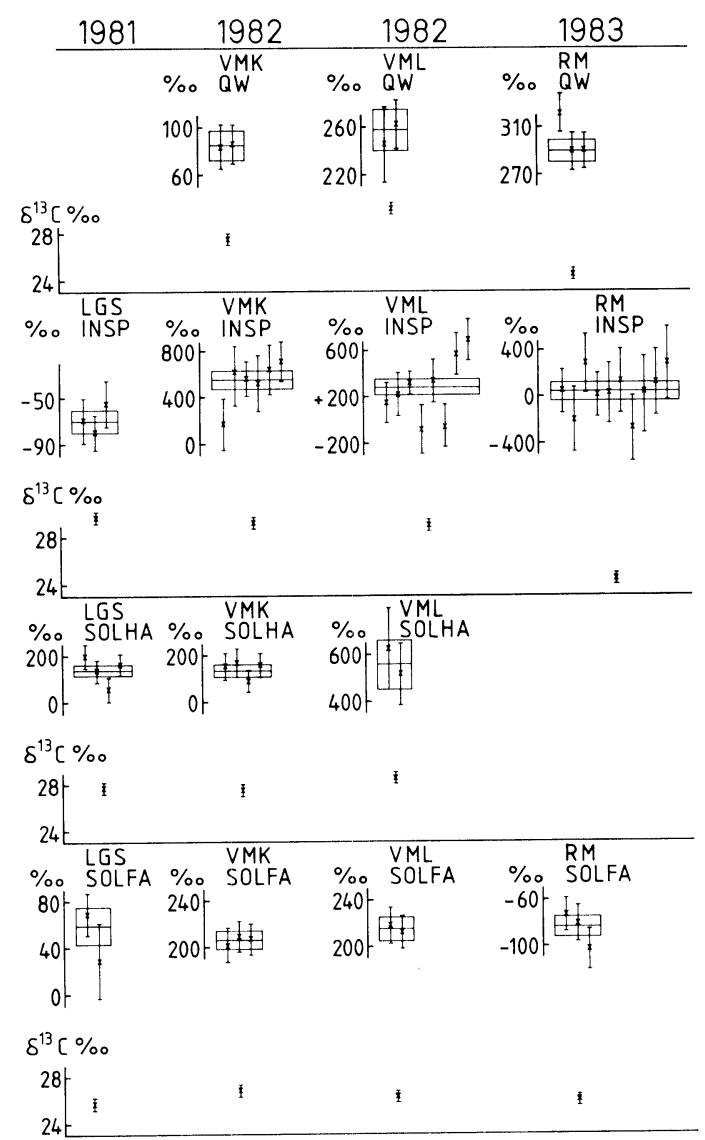

Fig 1 . Results of the ${ }^{14} \mathrm{C}$ measurements of the water samples. Bars indicate $\pm 1 \sigma$ and rectangles the weighted mean value of the single counting periods (usually one day and one night). 

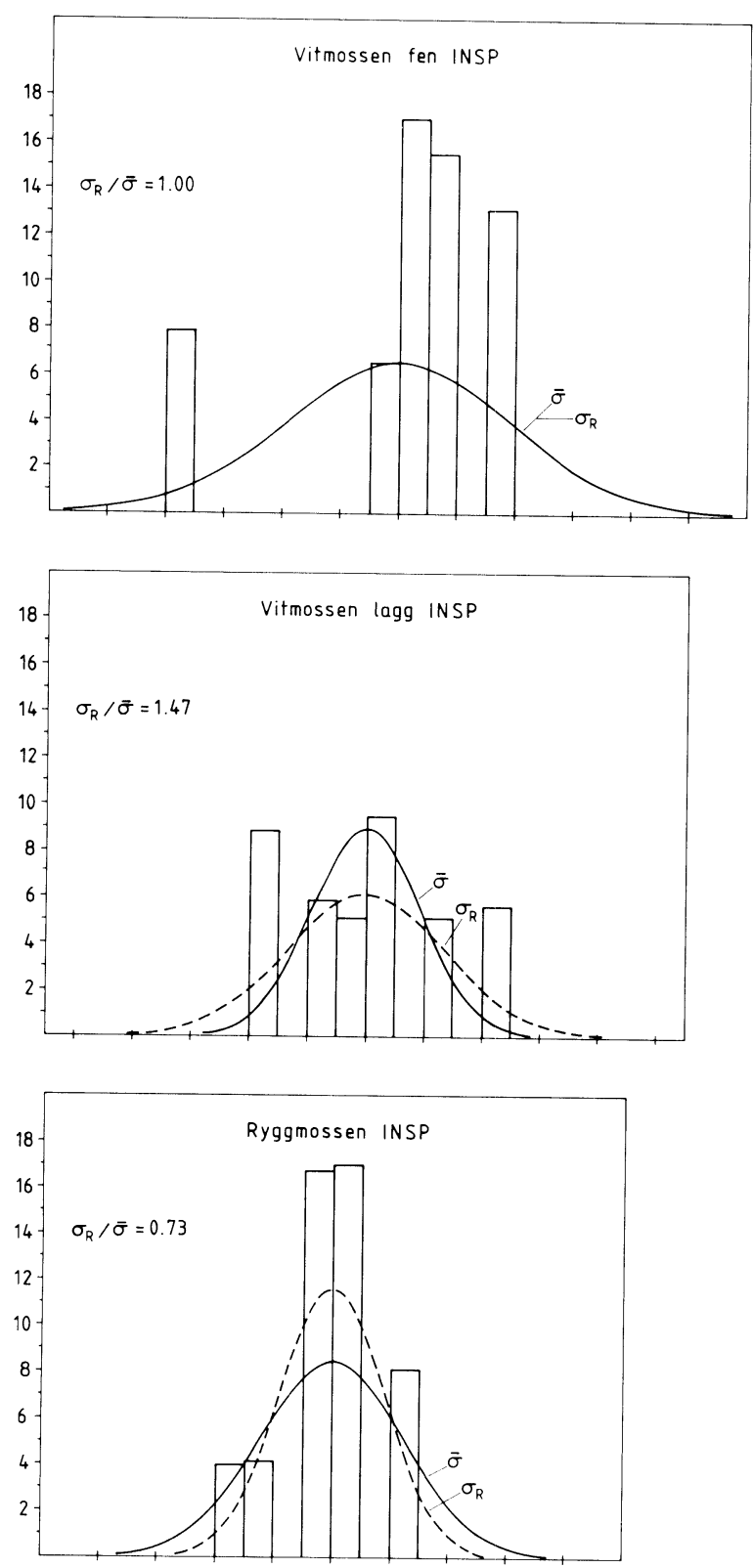

Fig 2. Statistical analysis of ${ }^{14} \mathrm{C}$ measurements for three samples 


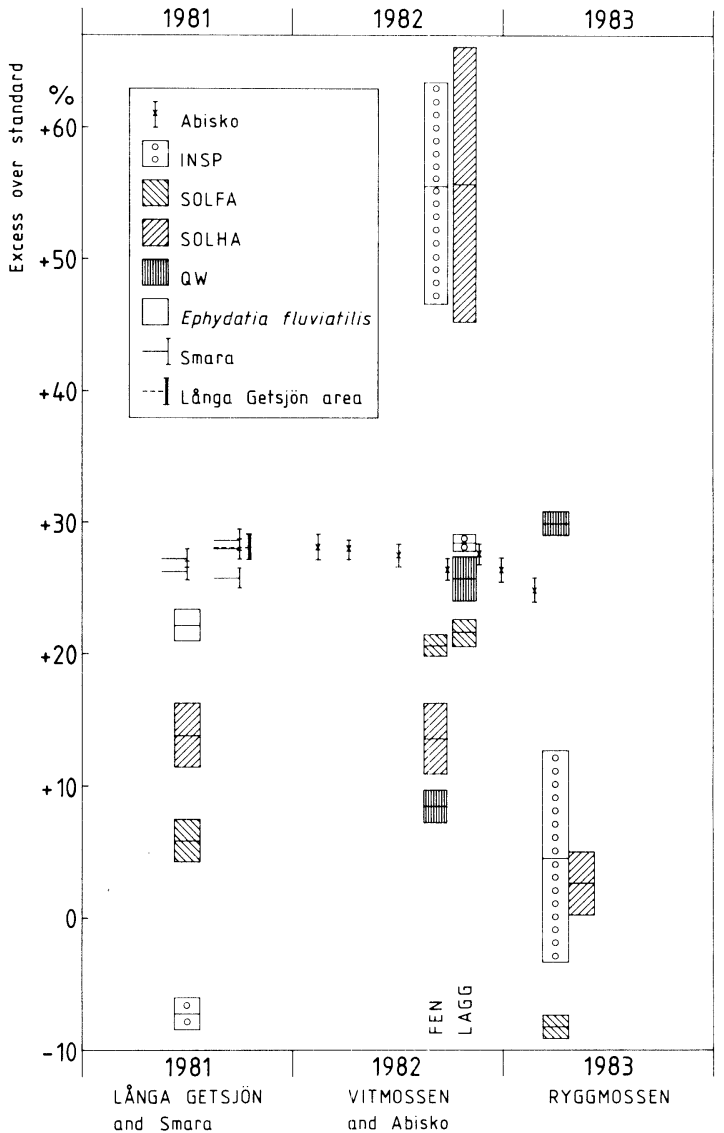

Fig 3. Results plotted together with ${ }^{14} \mathrm{C}$ activity of the atmosphere as measured on $\mathrm{CO}_{2}$ from the air collected in Abisko in northern Sweden, various plant materials gathered a Smara close to Uppsala, and one sample from Långa Getsjön. Atmospheric and terrestrial samples are plotted to indicate the time when the $\mathrm{CO}_{2}$ was absorbed or assimilated.

TABLE 2

Weighted mean activity for the fractions INSP, SOLHA, and SOLFA per mil over the international ${ }^{14} \mathrm{C}$ standard

\begin{tabular}{llccc}
\hline Sample type & \multicolumn{1}{c}{ Locality } & $\begin{array}{c}\text { Colln } \\
\text { yr }\end{array}$ & $\begin{array}{c}\text { Excess } \\
{ }^{14} \mathrm{C}( \pm 1 \sigma)\end{array}$ & $\begin{array}{c}\text { Coll water } \\
(\mathrm{L})\end{array}$ \\
\hline Lake water* & Långa Getsjön & 1981 & $36 \pm 12$ & 320 \\
Fen water & Vitmossen & 1982 & $208 \pm 8$ & 165 \\
Lagg water & Vitmossen & 1982 & $221 \pm 10$ & 165 \\
Bog water & Ryggmossen & 1983 & $-67 \pm 12$ & 330 \\
\hline \multicolumn{1}{c}{$*$ Submerged sample } & Långa Getsjön & 1981 & $222 \pm 12$ &
\end{tabular}


The various amounts of dissolved and fine particulate organic matter recovered in this investigation (Table 1) may be used for weighting a mean ${ }^{14} \mathrm{C}$ activity. Table 2 shows that the lake water has a mean enrichment of $36 \%$, the fen $208 \%$, the lagg $221 \%$, and the raised bog $-67 \%$ relative to the (AD 1950) dating standard. A submerged sample, Ephydatia fluviatilis, was collected in 1981 from Lake Långa Getsjön. It had a ${ }^{14} \mathrm{C}$ excess over the standard of $222 \%$, $i e$, ca $50 \%$, less than the contemporaneous atmospheric activity. The ash from this sample was mainly composed of diatoms as was the ash from the sediment (Olsson \& Florin, 1980). Some samples from this investigation contained a great many diatoms.

The carbon yield from $300 \mathrm{~L}$ of water is so little that further studies should be made using accelerator ${ }^{14} \mathrm{C}$ measurements to reduce the time spent on collection and preparation (Possnert \& Olsson, 1984).

\section{DISCUSSION}

Under normal circumstances (pre-bomb era) the activities of the examined fractions are expected to be somewhat lower than that of the atmosphere because of the influence of decaying organic material. If the effect is small-material deriving from the last 20 years - the activities measured in this investigation would have been higher than that of the atmosphere due to the bomb effect. An activity corresponding to that of the contemporary atmosphere may reflect a mixture of very recent and old material. The relative ${ }^{14} \mathrm{C}$ deficiencies found in this investigation must be taken as clear evidence for the risk of obtaining conventional ${ }^{14} \mathrm{C}$ ages that are too old for deposits in lakes, fens, and even raised bogs. In bogs the effect must be small and the influence of roots may counteract or even overcompensate for the proposed aging effect (Olsson \& Florin, 1980). Since some plants take up the greater part of the carbon dioxide they use from the sediment via their roots, the composition of the sediment and the accumulation rate may be of importance, resulting in various apparent reservoir ages. Investigations along these lines are underway in the Uppsala Laboratory. Lobelia dortmanna showed different ${ }^{14} \mathrm{C}$ activities at two different places in Lake Siggeforasjön and both values are lower than for some submerged Myriophyllum. The present investigation may, however, be taken as a recommendation to date, where possible, well-defined plant remains instead of the bulk sediment. This applies especially to deposits containing little organic carbon, where small amounts of graphite may contaminate the sample and cause the ages to appear much too old. A $5 \%$ deficiency in the mean activity cannot be interpreted to yield a figure for a reservoir age. There obviously is, however, some memory effect.

It should be mentioned that peat in a charcoal horizon was dated ca 500 years older than the charcoal at an adjacent archaeologic site, Torsburgen (Engström, 1984; Påhlsson, 1984). The author has interpreted the age of the peat, classified as Cladium, as being too old. Cladium and Carex plants from Torsburgen Bog will be collected for ${ }^{14} \mathrm{C}$ measurement. Torsburgen is situated on Gotland in a very calcareous area. 


\section{ACKNOWLEDGMENTS}

I wish to express my sincere gratitude to Maud Söderman for assisting with measurements and statistical analysis, Birgitta Hansson for help in collecting and filtering the samples, and Tomas Kronberg for his contribution to all stages of this study. The Swedish Natural Science Research Council defrayed all costs, for which I am most grateful. Thanks are due Gertrud Chronberg for determining the submerged species, Maj-Britt Florin for checking that diatoms occurred in the samples, and Göran Possnert for the accelerator measurement.

\section{REFERENCES}

Engström, J, 1984, Torsburgen. Tolkning av en gotländsk fornborg: Aun, v 6, p 1-154.

Olsson, IU and Florin, M-B, 1980, Radiocarbon dating of dy and gyttja in the Getsjö area, Kolmården, Sweden, to determine the rational limit of Picea: Boreas, v 9, p 289-305.

Påhlsson, I, 1984, Pollenanalytiska undersökningar från Torsburgsområdet, in Engström, J, Torsburgen. Tolkning av en gotländsk fornborg: Aun, v 6, p 142-146.

Possnert, $G$ and Olsson, IU, 1984, First Nordic colloquium on accelerators and dating, March 11th-12th, 1983: Boreas, v 13, p 365-375.

Stuiver, M, 1982, A high-precision calibration of the AD radiocarbon time scale: Radiocarbon, v 24, p 1-26. 